\title{
EFICIÊNCIA DO ALMOXARIFADO NA GESTÃO DE ESTOQUE
}

\author{
EFFICIENCY OF WAREHOUSE IN STOCK MANAGEMENT
}

\author{
Thales Luis Ramos de Oliveira- thales.1.r.oliveira2010@gmail.com \\ Faculdade de Tecnologia de Taquaritinga - Taquaritinga - São Paulo - Brasil \\ Carla Regina Lanzotti-carla.lanzotti@fatecbb.edu.br \\ Faculdade de Tecnologia de Taquaritinga - Taquaritinga - São Paulo - Brasil
}

DOI: 10.31510/infa.v18i1.1131

Data de submissão: 16/04/2021

Data do aceite: 09/07/2021

Data da publicação: 30/07/2021

\begin{abstract}
RESUMO
Diante do cenário global, muitas organizações necessitam aplicar fundamentos de gestão para coordenar de forma precisa a cadeia de suprimentos. Atualmente é considerada uma das estratégias fundamentais para a empresa. A gestão de estoque gerencia o planejamento e controle da aquisição de insumos, para atender a produção de novos bens ou serviços, além de estabelecer os métodos de reposição em suprir os materiais utilizados na empresa. Esse artigo tem como o objetivo principal demonstrar o papel do almoxarifado em uma indústria que produz redutores de velocidade. Assim, este estudo se propõe a realizar uma revisão bibliográfica e apresentar um estudo de caso, desenvolvido na empresa WEG-CESTARI. Com o desenvolvimento desse trabalho pode-se verificar que a aplicação dos indicadores de eficiência resulta nas melhorias de estoque, desde o endereçamento adequado até a utilização de inventário cíclico para o seu controle, podendo concluir que essas ações reduziram os valores dos índices de falhas na separação de peças para montagem.
\end{abstract}

Palavras-chave: Gestão de estoque. Métodos de reposição. Almoxarifado. Inventário cíclico.

\begin{abstract}
In de face of the global scenario, many organizations need to apply management fundamentals to precisely coordinate the supply chain. It is currently considered one of the fundamental strategies for the company. Stock management manages the planning and control of the acquisition of inputs, to meet the production of new goods or services, as well as establishing the replacement methods to supply the materials used in the company. This article aims to demonstrate the role of the warehouse in an industry that produces speed reducers. Thus, this study proposes to carry out a bibliographic review and present a case study, developed at the company WEG-CESTARI. With the development of this work it can be verified that the application of efficiency indicators results in stock improvements, from the appropriate addressing to the use of cyclical inventory for its control, It can be concluded that these actions reduced the values of the failure indices in the separation of parts for assembly.
\end{abstract}


Keywords: Stock management. Replacement methods. Warehouse. Cyclical inventory.

\section{INTRODUÇÃO}

O investimento na gestão de estoque representa uma vantagem competitiva para a empresa, que busca atender e garantir que o produto seja entregue aos seus clientes nos prazos estabelecidos. O objetivo do almoxarifado apresentado no estudo de caso é armazenar os materiais que são usados para o consumo da fábrica ou para atender as ordens de produção (OP'S) e ordens de montagem (OM'S).

O estoque é de extrema importância para suprimir a necessidade da demanda e garantir o prazo de entrega estabelecido ao cliente, sem comprometer o nível de serviço. O conceito de gestão aplicado ao estoque é um estudo sobre a capacidade de operar a quantidade de materiais pela programação da produção em relação a quantidade alocada.

Desta maneira, o objetivo principal deste trabalho é demonstrar o papel do almoxarifado em uma indústria que produz redutores de velocidade. Assim, este estudo se propõe a realizar uma revisão bibliográfica e apresentar um estudo de caso desenvolvido na empresa WEGCESTARI, mostrando como uma adequada gestão de estoque trouxe melhorias para a empresa estudada.

Assim, para uma melhor estruturação do trabalho, o mesmo foi dividido em seções, sendo estas: a Seção 2, que apresenta as características e o funcionamento adequado do Almoxarifado; a Seção 3, apresenta conceitos sobre a gestão de estoque; a Seção 4 que descreve os Resultados e Discussão que apresenta um estudo de caso sobre a eficiência aplicada no almoxarifado e, por fim, a Seção 5 que aborda as considerações finais deste trabalho.

\section{ALMOXARIFADO}

O almoxarifado está diretamente ligado à movimentação do transporte interno de materiais, aplicação de métodos adequados para estocar matéria-prima, peças em processo, materiais comprados e produtos acabados. 
Ferreira (2016, p. 88) afirma que "[...] as organizações se utilizam do processo de armazenagem para atender as necessidades dos clientes, sendo assim, a armazenagem é uma estratégia da organização perante o nível de serviço definido junto ao seu mercado."

A dimensão e as características desses materiais e produtos exige uma adequação para armazenagem. O método FIFO (First In First Out), por exemplo, classifica o armazenamento desses produtos de acordo com o recebimento, onde permite saber qual será o material a ser consumido primeiro. Este método também é utilizado para otimizar o processo de armazenagem e utilizar o espaço do armazém de forma eficaz.

O principal objetivo do almoxarifado é assegurar que o material esteja armazenado em local apropriado. Ainda, durante o recebimento, é necessária a conferência desses materiais, para que estejam de acordo com o que foi comprado, analisando também se a quantidade recebida está correta.

Além de registrar em sistema próprio, para garantir a correta quantidade disponível em estoque, as notas fiscais recebidas são encaminhadas para o setor de Contabilidade, para que todas as providências sejam tomadas.

\subsection{Planejamento e Controle da Produção.}

“A função da produção na organização representa a reunião de recursos destinados à produção de seus bens e serviços. Qualquer organização possui uma função produção porque produz algum bem ou serviço [...]” (SLACK, 2002, p. 33).

O PCP está diretamente ligado aos processos do almoxarifado, a função é centralizar a programação de entrega e armazenamento de materiais ou serviços. Esses recursos podem servir para atender os suprimentos de materiais, junto com os dados de produção de peças manufaturadas.

“O PCP está encarregado da coordenação e aplicação dos recursos produtivos, de forma a atender os planos estabelecidos em níveis estratégico, tático e operacional[...]” (VIEIRA, 2009, p. 107).

Qualquer operação produtiva requer um plano de controle, isso concilia o fornecimento e demanda em relação ao tempo, o cronograma destas atividades são planejadas para suprimir as necessidades em atender as ordens de produção, conforme apresentado pela Figura 1. 
Figura 1: Função do planejamento e controle concilia o fornecimento de produtos e serviços

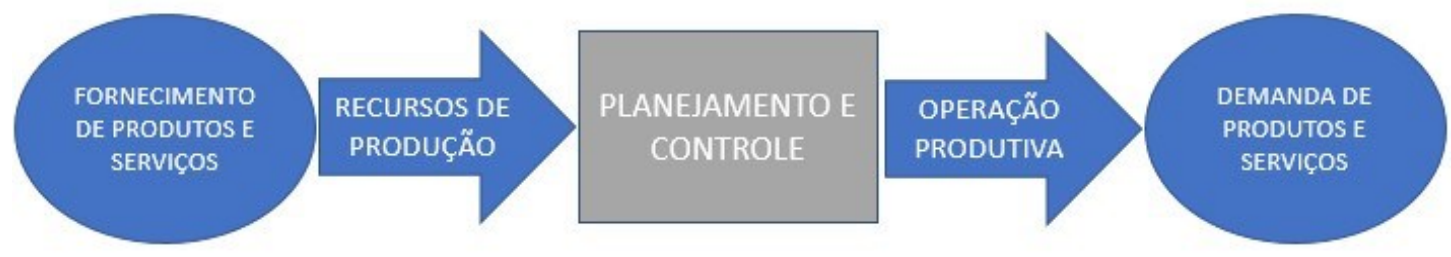

Fonte: Adaptação Slack (2002, p. 313)

\section{GESTÃO DE ESTOQUES}

De acordo com Tadeu e Rocha (2010, p.8), o estoque pode ser definido como "um conjunto de bens físicos e acumulados pela empresa e tratados como ativo e, portanto, possuem valor atrelado, características próprias e são conservados durante algum tempo". Desta maneira é necessário que o estoque deve ser constantemente monitorado, evitando a falta ou excesso de materiais.

"O gerenciamento de estoques abrange políticas e procedimentos que orientam as decisões [...]" (BOWERSOX, 2007, p. 270).

A gestão de estoques compreende uma série de atividades que envolvem desde o planejamento e programação das atividades de materiais em estoque até o controle das quantidades adquiridas, no sentido de mensurar a sua movimentação, armazenagem, localização e utilização desses estoques de forma a atender regularmente aos clientes quanto a quantidade, qualidade, preços e prazos. (FILHO, 2006, p. 63).

Outro aspecto a ser considerado na gestão de estoque é a acurácia de estoque que, de acordo com Bertaglia (2006, p. 319) "é determinada pela relação entre a quantidade física existente no armazém e aquela existente nos registros de controle". Assim, a acuracidade de estoques garante que não haja discrepância entre o número de itens que o sistema possui com o estoque real da empresa.

Os inventários são importantes para a empresa, pois avaliam a real quantidade de estoque físico, o que permite a identificação nas faltas de materiais.

O uso do inventário cíclico na gestão de estoque permite o controle conciso em relação aos materiais que são mais utilizados para o consumo, sendo assim aplicados diariamente para o armazenamento correto e o uso necessário para atender a produção. 


\subsection{Layout do armazém}

Para que as indústrias tenham uma melhor produtividade, suas áreas precisam estar sincronizadas para facilitar a movimentação de materiais em todas as etapas do processo produtivo. Assim, a atividade de manuseio de materiais deve trabalhar na escolha do layout adequado, na localização de materiais e na determinação das docas e pátios de carga.

De acordo com Luchezzi (2015), para a definição do layout do armazém, é necessário buscar o equilíbrio entre a utilização do espaço e os custos do manuseio dos materiais. $\mathrm{O}$ autor também afirma que deve ser considerada a profundidade de prateleiras, a largura de corredores, o tamanho para empilhamento, além da escolha do tipo de equipamento de movimentação a ser utilizado, além do uso de endereçamento para mostrar o local correto do armazenamento do produto ou peça, além adequada identificação do item.

No layout de armazém, apresentado pela Figura 2, é possível classificar os corredores por ruas, os porta-paletes em prédios e as prateleiras em andares, no exemplo a seguir:

Figura 2: Demonstração do endereçamento no layout de armazém

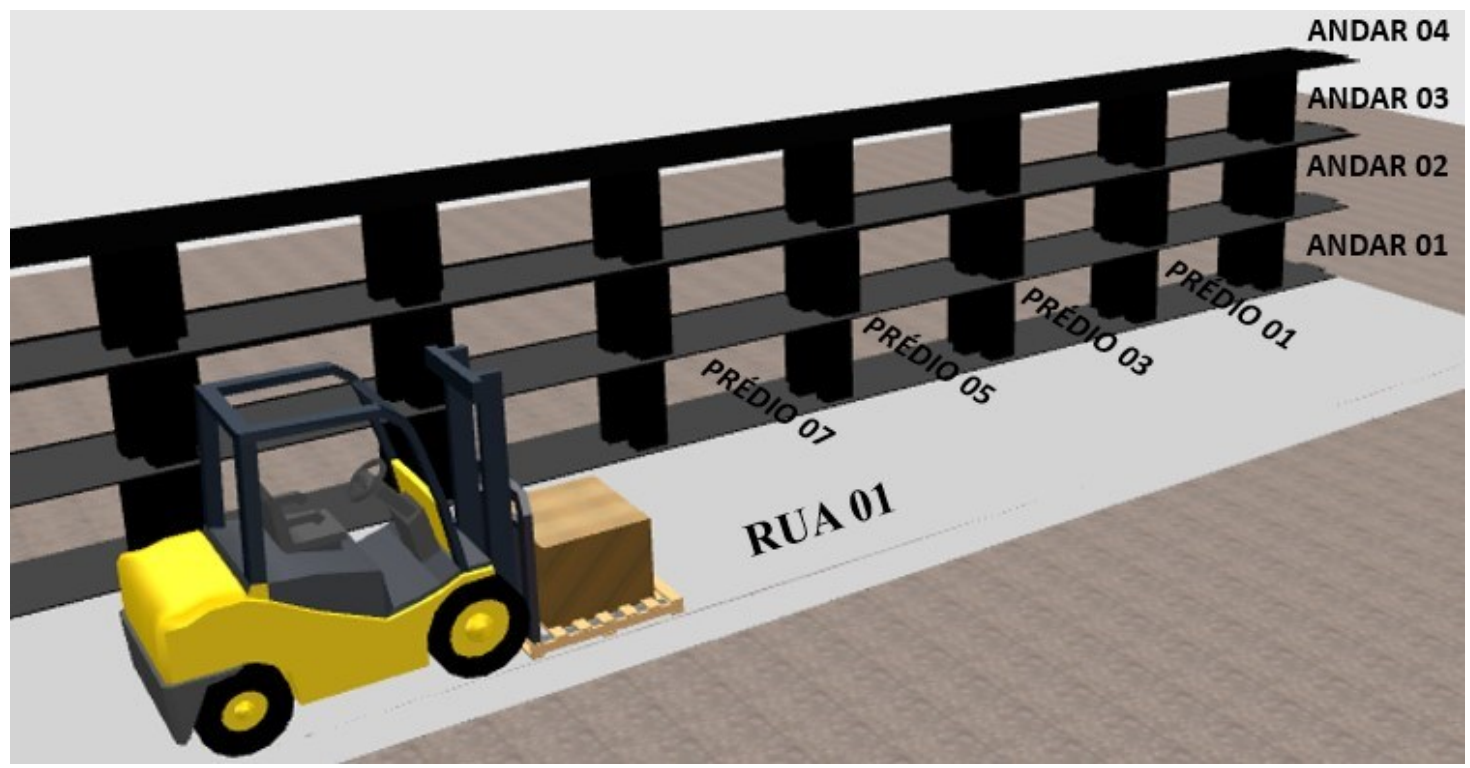

Fonte: Elaborado pelo autor (2021)

\subsection{Métodos de reposição}

Para suprimir a demanda de material, o método de reposição de estoque é executado através da requisição de materiais e abertura de pedidos de compra. 
Para que seja aplicado com mais exatidão, o uso do estoque de segurança equilibra os custos de estoque e a falta de itens para suprimir a necessidade. É a quantidade mínima de materiais que existe no estoque físico, de forma ininterrupta capaz de eliminar risco de atraso.

A eficácia do gerenciamento dos estoques pode ter grande influência na lucratividade da empresa. A capacidade de gerenciar estoques determina diretamente os níveis de estoques necessários para atingir os níveis de serviços desejados. Um gerenciamento de estoques eficaz pode também resultar no aumento das receitas de vendas. (BOWERSOX, 2007, p. 272).

O ponto de reposição define a demanda média em estabelecer o controle de compra, a aplicação desses conceitos impede a ruptura do estoque em relação a materiais para serem suprimidos para o processo produtivo.

A empresa precisa obter informações necessárias dos indicadores através do banco de dados, sobre os materiais que suprem a necessidade da demanda para atender o processo produtivo. Isso necessita obter pedidos de reposição, pedido de reserva e importação de produtos originados de outro país.

Em cada ponto no sistema de estoque, os gerentes de produção precisam gerir as tarefas do dia-a-dia dos sistemas. Pedidos serão recebidos dos consumidores internos e externos; eles serão despachados, e a demanda vai gradualmente consumir o estoque. Serão necessárias colocações de pedidos para reposição de estoques, entregas vão chegar e requerer armazenamento. (SLACK, 2002, p. 384).

Uma das ferramentas principais que ajudam nesse processo de informações é o conceito da curva $\mathrm{ABC}$, isso resulta na quantidade demandada para atender a produção de novos produtos e também os mais consumíveis para a organização. O Princípio de Pareto nos aponta a porcentagem dos itens de maior importância e proporciona um controle mais preciso. Ajuda a focar nos produtos mais recorrentes na empresa.

- Categoria A: $20 \%$ dos produtos correspondem a $80 \%$ do estoque;

- Categoria B: $30 \%$ dos produtos correspondem a 15\% do estoque;

- Categoria C: $50 \%$ dos produtos correspondem a 5\% do estoque.

\section{RESULTADOS E DISCUSSÃO}

A WEG-CESTARI é uma empresa que atua no desenvolvimento de redutores de velocidade, aplicados em acionamentos mecânicos nos setores sucroalcooleiro, agroindústria, 
mineração, metal mecânica, plástico, borracha, petroquímica, petróleo e gás. A Figura 3 apresenta o parque fabril da empresa, localizado em Monte Alto.

Figura 3: Vista aérea do parque fabril da WEG-CESTARI

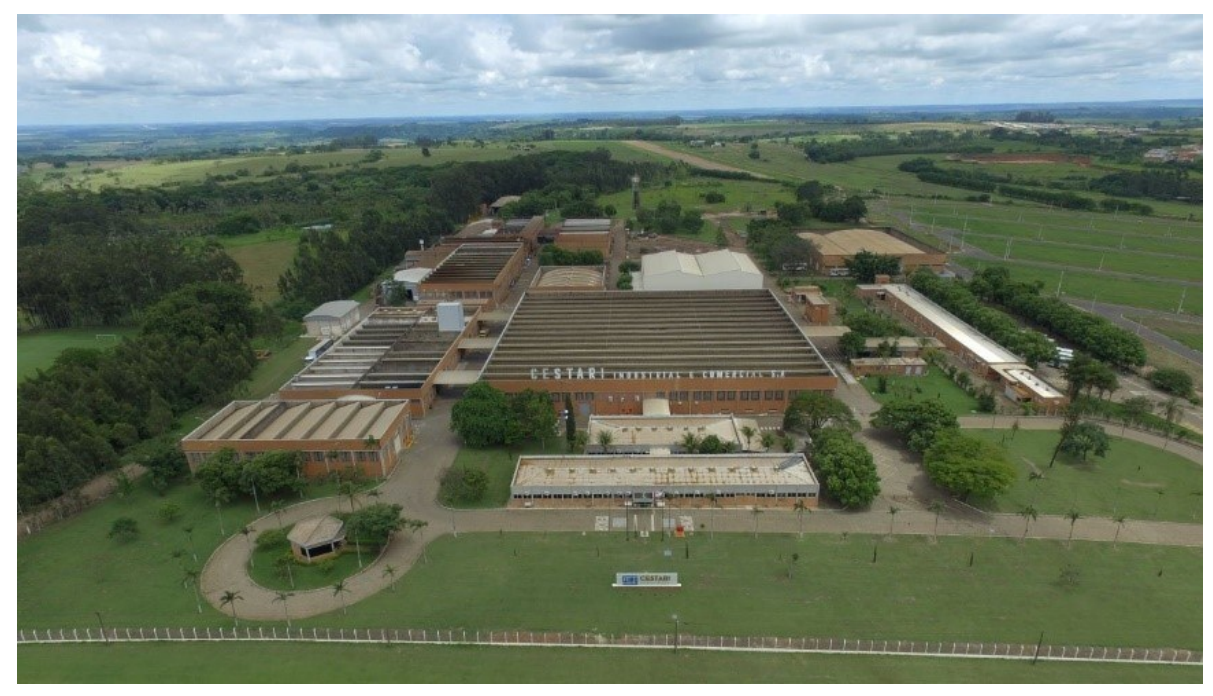

Fonte: WEG-CESTARI (2020)

A empresa possui diversos almoxarifados que contribuem para melhor adequação do armazenamento. Os itens mais utilizados na armazenagem são os materiais usinados (eixo, coroa, pinhão, engrenagem), materiais fundidos (carcaças, flanges, tampas de inspeção) e os materiais comprados (rolamentos, retentores, parafusos).

Há materiais que são fabricados por empresas terceirizadas, como calhas de óleo, flanges de motores, carcaças e tampas em alumínio. No caso de materiais fundidos, precisam ser encaminhados para o tratamento térmico e logo em seguida para usinagem.

A etapa de separação de materiais da empresa é responsável pela retirada de pedidos, por meio de OM'S e OP'S, que serão encaminhados por carrinhos ou paletes até a linha de montagem. Essa programação de montagem é emitida pela equipe de PCP, que define o atendimento no curto prazo estabelecido os pedidos para o cliente final, evitando que haja imprevistos durante o processo de montagem.

A utilização de carrinhos para movimentar os materiais até a linha de montagem, foi implantada para proteger as peças do almoxarifado. Para a movimentação de redutores de grande porte é necessário o uso de paletes e caixas de papelão para proteger os itens do redutor.

O processo de separação é feito através do relatório de programação da montagem para conferência. A empresa possui diversas linhas de montagem para cada redutor específico, como apresenta a Figura 4: 


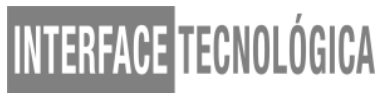

Figura 4: Elaboração da programação da montagem

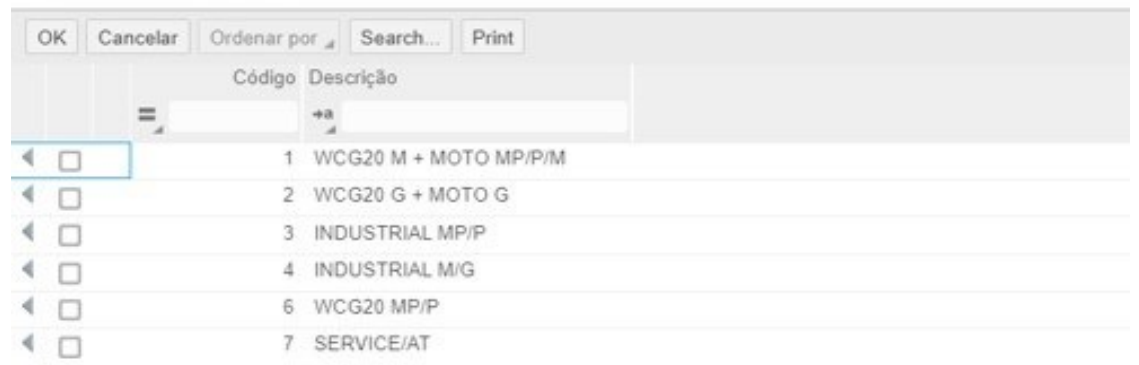

Fonte: Sistema LN da WEG-CESTARI (2021)

Assim que é determinada a seleção da linha que será emitido o relatório, é necessário selecionar o almoxarifado e imprimir os relatórios na programação de montagem, como apresentado pela Figura 5.

Figura 5: Impressão do relatório de programação da montagem para separação

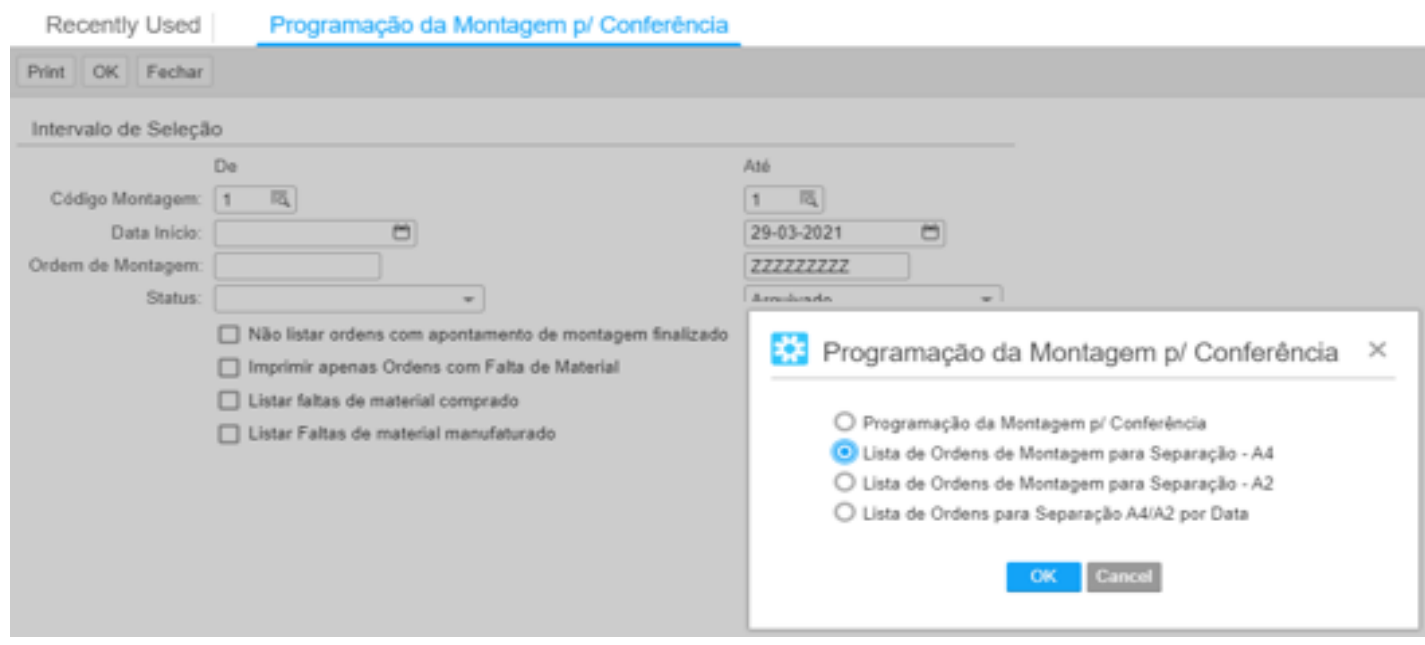

Fonte: Sistema LN da WEG-CESTARI (2021)

A afinidade entre o processo de separação e a etapa de conferência, busca analisar as peças que estão endereçadas, sendo que este endereçamento estará descrito no relatório de separação, juntamente com o saldo disponível no estoque, ação essa que auxilia na conferência da quantidade de cada peça nos almoxarifados.

Durante o processo de separação, existe a possibilidade de falta de peças para completar as $\mathrm{OM}^{\prime} \mathrm{S}$ e OP'S. Quando ocorre essa circunstância, assim que esses produtos entrarem no estoque, será realizada a retirada de faltas dessas ordens abertas, devido à espera no armazenamento deste produto, isso pode resultar em atrasos de entrega ao cliente. 


\section{1 Índice de eficiência}

O índice de eficiência contribui na organização e adequação para o armazenamento. Devido ao grande número de peças estarem em locais inapropriados, foram aplicados os indicadores de eficiência nos Almoxarifados A2 e A4.

Para que possa atender a demanda, os almoxarifados usam os indicadores para restabelecer uma melhoria, seja em um layout ineficaz que prejudica a identificação das peças, ou em falhas de armazenamento.

A análise apresentada neste estudo de caso foi realizada por meio da comparação do Almoxarifado A4 nos meses de março de 2020 e 2021. Essa proposta foi realizada para tentar diminuir as reclamações na linha de montagem, em relação às peças que não estavam de acordo com a OM.

Por meio desta análise, foi possível analisar as peças com imprecisões no estoque. No período analisado conforme apresentado pela Figura 6, o item rolamento apresentou o maior índice de discrepância, tanto na parte de identificação quanto no armazenamento. Portanto foi aplicada a alteração de endereço para um local mais adequado, resultando na diminuição dos índices de divergência desse material.

Analisando a Figura 6, é possível verificar a quantidade de falhas ocorridas nos meses de março de 2020 e 2021, além das peças nas quais foram aplicadas uma melhoria, grande parte desses itens não tinham local apropriado ou estavam sem identificação do código de produto, isso fez com que as falhas diminuíssem durante este período de mudanças na armazenagem.

Figura 6: Comparação entre o mês de março 2020 e março 2021
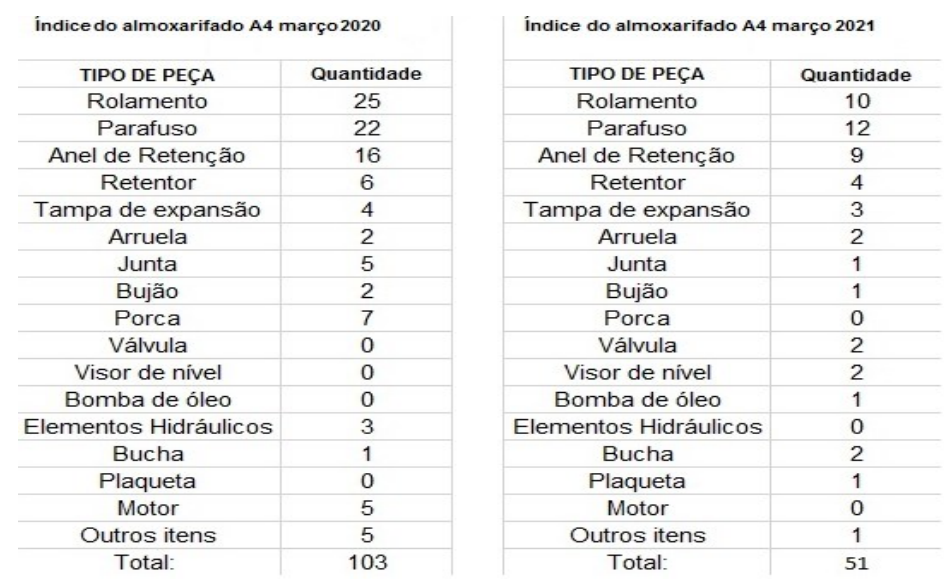

Fonte: Elaborado pelo autor (2021) 
Além do item rolamento, o item anel de retenção também passou por adequações, uma vez que a maioria não possuía uma identificação, o que resultava na ineficácia da separação das OM'S.

A Figura 7 apresenta a forma de alocação de cada anel de retenção após a adequação, pode-se destacar que atualmente todos os itens estão identificados e armazenados no lugar determinado, favorecendo a redução da divergência.

Figura 7: Local da armazenagem dos anéis de retenção

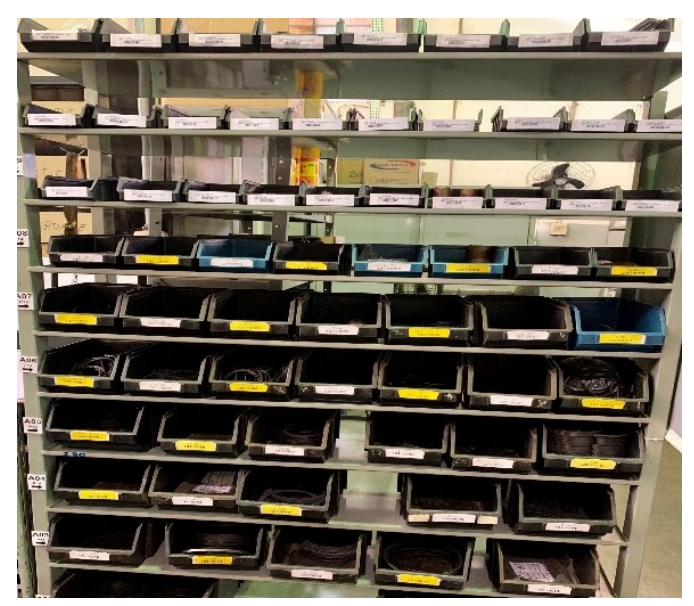

Fonte: Almoxarifado A4 da WEG-CESTARI (2021)

Pode-se afirmar que o processo de melhoria implantado e apresentado neste estudo de caso deve ser contínuo, uma vez que todas as discrepâncias devem ser analisadas, para que não voltem a ser repetidas. Além que é necessário sempre analisar o estoque para que a peça seja utilizada no produto.

\subsection{Inventário cíclico na capacitação de melhoria}

Para que todo o processo de produção seja realizado corretamente, o estoque do almoxarifado deve ser confiável para que não ocorra nenhum imprevisto de atraso. A ausência de material pode provocar atrasos de entrega ao cliente final.

Para tentar minimizar o risco, a empresa analisada aplica o uso do inventário cíclico. Para exemplificar, a Tabela 1 apresenta o inventário do item anel de retenção, apresentando a quantidade presente no estoque físico e a quantidade verificada no sistema de gestão de estoque. Analisando as informações contidas na Tabela 1, pode-se verificar que o anel de retenção E055 possui três peças em falta, o que pode significar que ocorreu uma falha em alguma OM, que 
não foi realizada a baixa da peça no sistema ou que pode haver algo pendente numa ordem de trabalho para atender a assistência técnica.

Assim, por sua vez que ocorre este tipo de falha, é realizado o controle no acesso aos materiais, realizando a conferência do estoque físico.

Tabela 1: Conferência dos anéis de retenção no estoque físico

\begin{tabular}{c|c|c|c|c}
\hline \multicolumn{5}{c}{ Inventário dos Anéis de retenção } \\
\hline Descrição & Código & $\begin{array}{c}\text { Quantidade } \\
\text { Estoque Físico }\end{array}$ & $\begin{array}{c}\text { Quantidade } \\
\text { Estoque Sistema }\end{array}$ & Acuracidade \\
\hline ANEL RETENÇÃO DIN0472 1070 & 13110065 & 41 Peças & 25 Peças & 16 Peças \\
\hline ANEL RETENÇÃO DIN0472 E055 & 13110039 & 22 Peças & 25 Peças & -3 Peças \\
\hline ANEL RETENÇÃO DIN0472 1068 & 13110236 & 478 Peças & 450 Peças & 28 Peças \\
\hline
\end{tabular}

Fonte: Elaborado pelo autor (2021)

\section{CONSIDERAÇÕES FINAIS}

A análise de estoques consiste no aprimoramento das informações necessárias para gerir de forma eficaz o estoque da empresa, desta maneira, a acuracidade do estoque é analisada diariamente, para minimizar danos causados pelas falhas. Isso possibilita na comparação entre a quantidade física e a quantidade no sistema. A aplicação do inventário cíclico é definida pelos próprios gestores da empresa.

A gestão de estoques é um conjunto de práticas que possibilitam a otimização da eficiência entre o volume de recursos financeiros estabelecidos e a quantidade de materiais alocados, sempre visando o atendimento da demanda.

A adoção de técnicas de avaliação de estoque permitiu a verificação do número de peças no almoxarifado capaz de atender a demanda na linha de produção, evitando perdas ou atraso na entrega ao cliente.

Após a aplicação das técnicas apresentadas, a empresa melhorou os índices de despesas gerenciáveis, resultando na redução de perdas e, consequentemente, na redução dos custos relacionados ao processo de fabricação dos produtos. 


\section{WTIEREAGETECWNOLOGGCA}

\section{REFERÊNCIAS}

BOWERSOX, J. Donald; CLOSS, J. David. Logística empresarial: o processo de integração da cadeia de suprimentos. 1. ed. São Paulo: Atlas, 2007.

FERREIRA, Leonardo; ASSIS, Rodrigo; CHIACHERINE, Luis; ESPOSITO, Valdir; BREDDA, Cristiano; KURTH, Romeu. Processos logísticos. 1. ed. Londrina: Educacional S.A., 2016.

FILHO, João Severo. Administração de logística integrada: materiais, PCP e marketing. 2. ed. Rio de Janeiro: E-papers, 2006.

LUCHEZZI, Celso. Gestão de armazenamento, estoque e distribuição. São Paulo: Pearson Education do Brasil, 2015.

SLACK, Nigel; CHAMBERS, Stuart; JOHNSTON, Robert. Administração da produção. 2. ed. São Paulo: Atlas, 2002.

TADEU, Hugo Ferreira Braga (org). Gestão de estoques: fundamentos, modelos matemáticos e melhores práticas aplicadas. São Paulo: Cengage Learning, 2010.

VIEIRA, Hélio Flávio. Gestão de estoques e operações industriais. Curitiba: IESDE Brasil S/A, 2009.

WEG-CESTARI. Institucional. Disponível em:

http://www.wegcestari.com.br/index.php/pt/institucional/weg-cestari. Acesso em: 30 mar. de 2021. 